\title{
NOCTUID MOTHS AS POTENTIAL HYBRIDIZATION AGENTS FOR PLATANTHERA ORCHIDS
}

\author{
Fabiana Esposito ${ }^{1}$, Thomas MerckX ${ }^{2} \&$ Daniel Tyteca $^{1,3}$
}

\begin{abstract}
${ }^{1}$ Orchid Research Group, Biodiversity Research Centre, Earth and Life Institute, Université catholique de Louvain (UCL), Croix du Sud 4-5 (L7.07.04), B-1348 Louvain-la-Neuve, Belgium

${ }^{2}$ Behavioural Ecology and Conservation Group, Biodiversity Research Centre, Earth and Life Institute, Université catholique de Louvain (UCL), Croix du Sud 4-5 (L7.07.04), B-1348 Louvain-la-Neuve, Belgium

${ }^{3}$ Corresponding author: e-mail: daniel.tyteca@uclouvain.be
\end{abstract}

ABSTRACT. Zoophilous flowering plants communicate with pollinators to ensure pollen transfer. Pin-pointing which species are effective pollinators is not only essential to better understand plant-pollinator networks, but equally so to better understand the potential of hybridization in plant systems, such as in orchids. As a case study, we studied two sympatric populations of the congeneric orchids Platanthera bifolia and P. chlorantha in order to assess their nocturnal pollinators by checking which moth species carried pollinaria, and of which orchid species. Moths carrying Platanthera pollinaria were photographed and identified. The carried pollinaria were identified and counted, and their attachment position on the moth's head was scored. Based on these observations we show that three species of noctuid moths visited the Platanthera inflorescences. Although Noctua pronuba visited P. chlorantha, only Cucullia umbratica and Autographa gamma turned out to be potential pollinators for both orchid species. As such, we here demonstrate that the latter two noctuids have high potential to facilitate hybridization among these two orchid species, especially so in sympatric populations.

KeY words: Autographa gamma; Cucullia umbratica; light traps; macro-moths; Platanthera; pollination.

Introduction. Zoophilous flowering plants communicate with pollinators, often specifically so by using specific floral rewards and signalling apparatus, to help ensure pollen transfer between conspecific plants (Wester \& Lunau 2016). Although pin-pointing which species are effective pollinators is essential to better understand the functioning and resilience of plant-pollinator networks (Kühsel \& Blüthgen 2015, Macgregor, Pocock, Fox \& Evans 2015, Weiner, Werner, Linsenmair \& Blüthgen 2014), direct observation (Peter et al. 2009, Raguso \& Willis 2005, Robertson \& Wyatt 1990) is time consuming - even via continuous video monitoring - since the proportion of visited flowers is often low. Moreover, findings obtained via direct observation are typically not fully trustworthy (Suetsugu \& Fukushima 2014 a, b). Thus, in general, foraging pollinators are identified via indirect methods, for example the identification of an orchid's pollinarium on moths' hairy bodies (Darwin 1877, Maad \& Nilsson 2004, Nilsson 1983). Such research is also essential to better understand the potential for hybridization in (orchid) plant systems
(Cozzolino \& Widmer 2005, Schiestl \& Schlüter 2009). Insects visiting orchid flowers can be divided into three main groups: (i) 'flower-visitors, which land on a flower, without any pollinaria attached to their body; (ii) 'potential pollinators', if pollinia adhere somewhere on the insect's body (e.g. antennae, head, abdomen), or if they are just likely to carry pollinaria to another flower, and (iii) 'effective pollinators', when pollinia attached to the insect's body are eventually deposited on the stigma of another flower (Bournérias et al. 2005, Ruiz 2009).

Moths, an insect group capable of pollinating a wide range of plant species, constitute the majority of nocturnal pollinators (Macgregor et al. 2014). However, as studies on networks of plants and their nocturnal pollen vectors are rare, the role of moths as pollinators is most likely underestimated (Hahn \& Brühl 2016). More specifically, moths are known to be the primary pollinators of orchids from the Orchidoideae subfamily (Catling \& Catling 1991, Hahn \& Brühl 2016). This is also the case for certain orchids of the Platanthera genus, such as the threatened 
P. praeclara native to the North American prairie, which are highly specialized for pollination by moths (i.e. moth pollination syndrome, or phalaenophily) (Argue 2012, Westwood \& Borkowsky 2004).

The Platanthera genus contains $c a .150$ species (Karasawa 2003) and is as such the largest genus of northern temperate terrestrial orchids (Hapeman, 1997, Hapeman \& Inoue 1997, Wood, Beaman \& Beaman 1993). Species belonging to this genus can be found in a wide range of environments, from grasslands to forest understories. They may show ecotypic variation due to co-evolutionary relationships with local pollinators, which are mostly represented by nocturnal moth species (Hapeman \& Inoue 1997). Noctuid and sphingid moths represent the majority of Platanthera pollinator species, but there are also some species that are pollinated by beetles, bumblebees, butterflies, flies and even mosquitos (Hapeman \& Inoue 1997, Inoue 1985, Nilsson 1983).

Within the framework of our research devoted to Platanthera in Belgium (Esposito, Jacquemyn, Waud $\&$ Tyteca 2016), we here focus on the observation of moth visitors of two Platanthera species, namely $P$. bifolia (L.) Rich. and P. chlorantha (Custer) Rchb. The $P$. bifolia group is of particular significance because it generated one of the classic textbook examples of presumed selection-mediated co-evolution between orchids and their pollinating insects (e.g., Bateman, James \& Rudall 2012, Hapeman \& Inoue 1997, Maad \& Nilsson 2004, Nilsson 1983, 1985). The flowers of Platanthera are strongly scented, and the scent emission, which happens in the late evening to night, matches the feeding times of many nocturnal moths (Nilsson 1983, Tollsten \& Bergström 1993). The two studied species differ in their floral scent composition, which may represent a cue, and which may hence explain the occurrence of different moth visitors (Nilsson 1983, Tollsten \& Bergström 1993). Also, the column morphology differs between both species, and a significant difference is also represented by the spur length (Darwin, 1862, Nilsson 1978, 1983, 1985), which plays an important role in pollination effectiveness (Bateman \& Sexton 2008; Claessens \& Kleynen 2006). Additionally, two morphological traits are especially discriminant between both species: the length of the caudicles and the distance between the viscidia (Nilsson 1983). The latter is particularly significant because it leads to the placement of pollinaria on different parts of the moths' heads (Claessens \& Kleynen 2006, Esposito, Vereecken, Rinaldi, Laurent \& Tyteca unpublished, Maad \& Nilsson 2004, Nilsson 1983, 1985, Schiestl \& Schlüter 2009). Generally, moths will probe deep into the spur to reach the nectar until the head comes into contact with the sticky discs at the base of the pollinaria. In Platanthera, only the visitors that present a suitable scale- or hairless part of the head may be able to touch the viscid disc when the head is forced against the spur mouth (Nilsson 1983). P. chlorantha's pollinaria generally stick to the eyes of pollinators, and those of P. bifolia to their proboscises (Nilsson 1978, 1983). Consequently, putative hybrids -possessing a column that is morphologically intermediate between the column structures of both species- are expected to interact imperfectly with the flower visitors due to the narrowly delimited surfaces on moths' heads that are suitable for attachment of viscidia (Claessens \& Kleynen 2006, Nilsson 1978). The fact that such intermediately placed pollinaria are not generally found on moths indicates that they regularly become detached, generally from the hairy labial palps of the moths (Nilsson 1983, 1985). Consequently, introgressive hybridization is considered rare and only of temporal and local occurrence. Nevertheless, hybridization has been reported in a few populations, such as in Scandinavia (Nilsson 1985), in southern England (Bateman 2005; Bateman \& Sexton 2008), in South Limburg, The Netherlands (Claessens, Gravendeel \& Kleynen 2008, Claessens \& Kleynen 2006) and in the upper valley of Lavant, Austria (Perko 1997, 2004). In the latter two situations, a large number of intermediate individuals were observed, even in the (quasi-) absence of parent species.

However, in a study that we conducted on two mixed populations of $P$. bifolia and P. chlorantha in Belgium, molecular data showed that hybridization and genetic admixture occurred only at a very low rate, despite the fact that species of both noctuids and sphingids have been observed visiting both $P$. bifolia and $P$. chlorantha (Claessens et al. 2008, Claessens \& Kleynen 2006, Nilsson 1983). Moreover, most morphologically intermediate individuals turned out to be genetically identical to P. bifolia, and could therefore not be identified as hybrids (Esposito et al. unpublished). 
Here, as a follow-up to this finding, we wanted to uncover the identity of effective pollinators able to visit these intermediate morphotypes in such sympatric populations. As such, we identified flowervisitors of the congeneric orchids Platanthera bifolia and $P$. chlorantha as well as the morphologically intermediate orchid individuals in these two mixed populations.

\section{Material and methods}

Study species. - Both P. bifolia and P. chlorantha species are rewarding, and their nectar is hidden deeply in their long spurs, and hence available only to pollinator species with long proboscises. Their flowering period in central Europe occurs between May and July and is partly overlapping in areas of sympatry (Delforge 2005). Both species show a significant different morphology of the column. $P$. bifolia displays a small column and two anther pockets that are set almost parallel to each other. Pollinaria are generally transferred by 'massulae' units (Johnson \& Edwards 2000). P. bifolia shows a distance between the viscidia of 0.2 to $1.1 \mathrm{~mm}$ and the pollinium shows a very short caudicle $(0.2-0.5 \mathrm{~mm})$; these characteristics imply that pollinia will be attached to the proboscis of pollinators. Pollinators of $P$. bifolia are mostly sphingids (Boberg, Alexandersson, Jonsson, Maad, Ågren \& Nilsson 2013, Nilsson 1983 , 1988). The column of $P$. chlorantha is wider with the anther pockets set strongly divergent at the base. Its pollinarium has a relatively long caudicle (1.2-2.2 $\mathrm{mm}$ ) with a distance between the viscidia varying between 2.3 and $4.9 \mathrm{~mm}$. This particular characteristic is considered an adaptation for attachment to the eyes of the pollinators (Maad \& Nilsson 2004), which are mostly represented by noctuid moths (Claessens \& Kleynen 2011, Nilsson 1978, 1983, 1985, Sexton 2014, Steen 2012). The distance between the viscidia of intermediate individuals is, on average, larger than in P. bifolia and smaller than in P. chlorantha (1.3$2.3 \mathrm{~mm}$ ).

The visual assessment method that allows the assignment of the visited Platanthera species based on the morphology of pollinaria and on their position on pollinators' head was proposed firstly by Nilsson (1983) and confirmed by the study of Claessens et al. (2008).
Study area and sampling. - The study was performed in the Calestienne region in southern Belgium, in 2013 and 2014. Floral visitors were recorded during the peak flowering times in two sympatric Platanthera populations on the 22nd of June 2013, again in one of these on the 27th of June 2013 and finally in the other sympatric site on the 3rd of June and the 4th of July 2014. Light traps were running from 21:00 $\mathrm{h}$ and checked early next morning from 04:00 h onwards. One of the mixed populations was located on a calcareous grassland (Tienne de Botton), while the other was located in a light birch-ash wood (Bois Niau). In order to catch pollen-vectors, we utilised light traps that have proven to be highly suitable for sampling moth communities (Heath 1965, Merckx et al. 2009a, b, Merckx, Marini, Feber \& Macdonald 2012a, Merckx et al. 2012b, Young 1997). Sampling moths with light traps has also some additional advantages in terms of cost and ease of use, compared to video monitoring for instance (Steen \& Mundal 2013).

Two light traps were deployed for each of the sympatric zones, where two Platanthera species and the morphologically intermediate individuals were growing intermixed, hence possibly sharing pollinators. Light traps were placed in close vicinity $(3-10 \mathrm{~m})$ to inflorescences in good flowering conditions. Moths were sampled using Heath pattern actinic light traps $(6 \mathrm{~W})$, which operate on the 'lobster-pot principle', whereby individuals are drawn to an actinic tube, which is secured vertically between baffles, fall unharmed down a funnel, and rest inside the trap (Fig. 1). At dawn, captured moths were checked for the presence of Platanthera pollinaria by visual assessment. To facilitate the identification of the species/type of pollinaria we utilised a Peak scale magnifier. Moreover, during two observations nights, we photographed moth individuals, which were seen visiting Platanthera species without the support of light traps. Moths bearing pollinaria were identified, whilst the type and number of pollinaria was accurately checked. Specifically, we measured the length of the caudicle of the pollinaria attached to the moths' heads. Additionally, moths carrying pollinaria were photographed with a digital camera (Canon Eos 7D, Nikon D-200). We lumped data obtained with and without light trapping for analyses. 


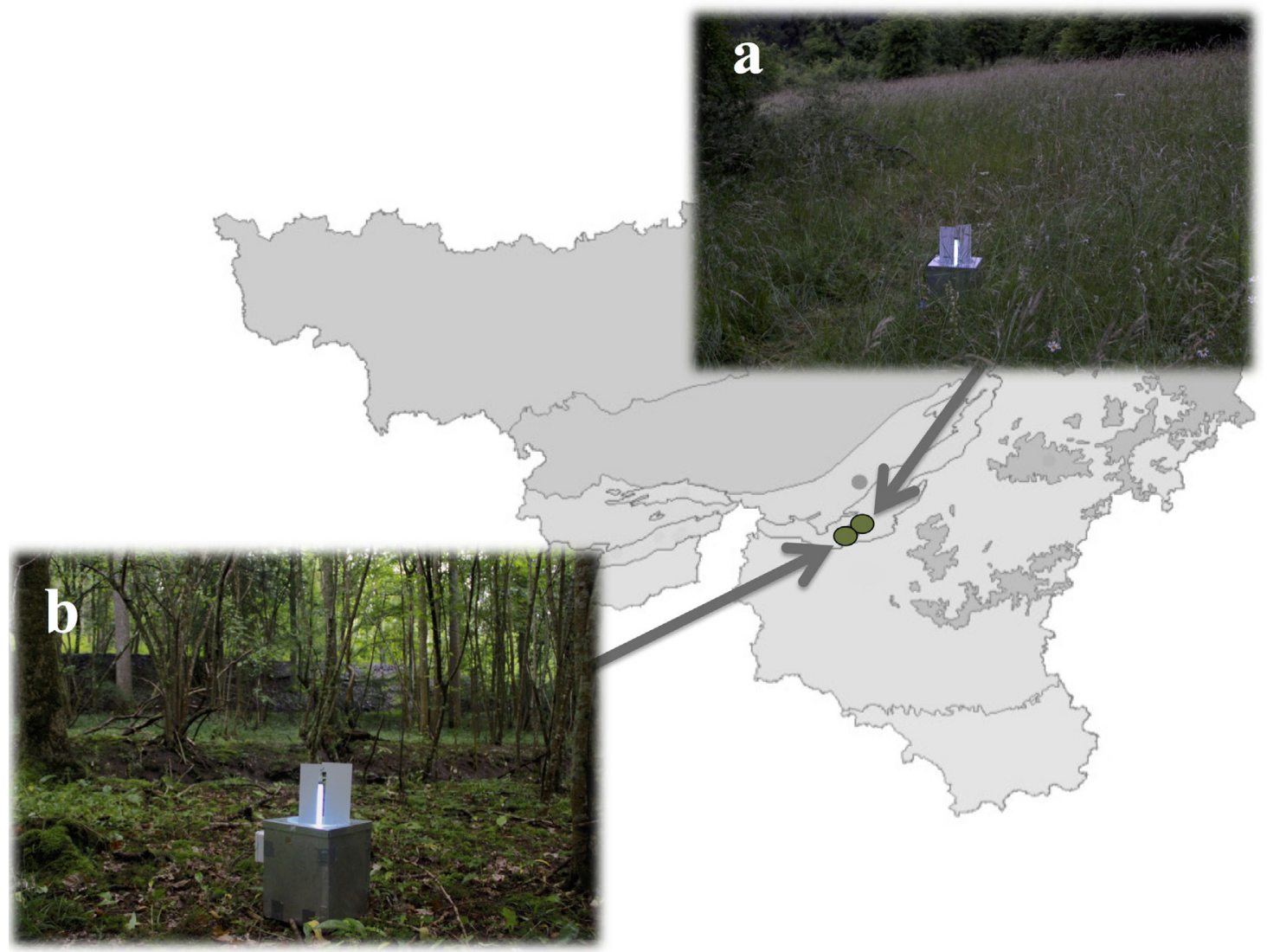

Figure 1. Map of Wallonia (Southern-Belgium) showing the locations of the sympatric populations of $P$. bifolia and $P$. chlorantha in the Calestienne region: (a) Botton and (b) Bois Niau (pictures F. Esposito). Pictures depict light traps at each location.

Results. Table SI1 gives the total number of nocturnal moths light-trapped during the observation nights at the sympatric sites of Botton and Bois Niau. On the whole, seven individuals from two mediumsized crepuscular-nocturnal species were carrying Platanthera pollinaria (Table 1).

Generally speaking, these observations show that pollinaria were carried according to expectations, i.e., one $P$. chlorantha pollinarium on the eye, two P. bifolia pollinaria on the proboscis, and one or two intermediate's pollinaria on the cheeks. The measurement of the length of each pollinarium determined the assignment (according to Nilsson's criteria 1983) to Platanthera species previously visited, and also confirmed the species attribution according to the position of pollinaria on the moths' heads (measurements of pollinia's length not shown).

These results also show that, in both sympatric locations, although the majority of species caught were belonging to the Geometridae family (Table 2), we only observed individuals of the Noctuidae family carrying Platanthera pollinia. More specifically, the total amount of moth species belonging to the Noctuidae family found with the pollinaria attached on the body was two species out of six. The only noctuid species found to carry intermediate's pollinaria turned out to be Cucullia umbratica.

Besides these light trap experiments, during two observation nights on 3rd June and 4th July 2014 at the Botton site, we managed to take a picture of a Cucullia umbratica moth visiting a $P$. chlorantha inflorescence with one pollinium attached to the cheek and (probably) two to the proboscis (Fig. 2F). Another visitor was also observed; this was Noctua pronuba with a pollinarium of $P$. chlorantha on the eye (Fig. 2G). 
TABLE 1. Overview of moth individuals observed carrying orchid pollinaria during four nights of monitoring. Superscript numbers in front of the moth species name indicate different individuals of moths.

\begin{tabular}{|c|c|c|c|c|c|c|}
\hline Date & Site & Plant species & $\begin{array}{l}\text { Number } \\
\text { pollinaria }\end{array}$ & Moth species & $\begin{array}{l}\text { Position } \\
\text { pollinaria }\end{array}$ & Figure \\
\hline \multirow[t]{3}{*}{$22 / 06 / 13$} & \multirow[t]{3}{*}{ Botton } & P. chlorantha & 1 & ${ }^{1}$ Cucullia umbratica & Eyes & $2-D$ \\
\hline & & Intermediate & 2 & ${ }^{2}$ Cucullia umbratica & Cheeks & $2-E$ \\
\hline & & P. bifolia & 2 & ${ }^{3}$ Cucullia umbratica & Proboscis & $2-C$ \\
\hline \multirow[t]{2}{*}{$22 / 06 / 13$} & \multirow[t]{2}{*}{ Bois Niau } & P. bifolia & 2 & ${ }^{1}$ Autographa gamma & Proboscis & - \\
\hline & & P. chlorantha & 1 & ${ }^{2}$ Autographa gamma & Eyes & - \\
\hline \multirow[t]{3}{*}{$27 / 06 / 13$} & \multirow[t]{3}{*}{ Bois Niau } & P. bifolia & 2 & ${ }^{1}$ Cucullia umbratica & Proboscis & $2-A$ \\
\hline & & P. bifolia & 2 & ${ }^{1}$ Cucullia umbratica & Proboscis & $2-A$ \\
\hline & & P. bifolia & 2 & ${ }^{2}$ Cucullia umbratica & Proboscis & $2-B$ \\
\hline \multirow[t]{2}{*}{$3 / 6 / 14$} & \multirow[t]{2}{*}{ Botton } & Intermediate & 1 & Cucullia umbratica & Cheeks & $2-\mathrm{F}$ \\
\hline & & P. bifolia & 2 & Cucullia umbratica & Proboscis & $2-F$ \\
\hline $4 / 7 / 14$ & Botton & P. chlorantha & 1 & Noctua pronuba & Eyes & $2-G$ \\
\hline
\end{tabular}

Discussion. The position and shape of the pollinaria attached to the caught moths proved sufficient to identify which orchid species had been visited, even if the visits themselves were not observed. One of the three observed moth species, Cucullia umbratica, here observed with pollinaria of $P$. bifolia and $P$. chlorantha, was already known to be a visitor of both Platanthera species (e.g. Nilsson 1978, 1983). However, contrary to the assumption of Nilsson (1983), who states that efficient transport of pollinaria on cheeks is impossible for putative hybrids, our observations in one of the sympatric populations show that the species visits flowers of intermediates, because their pollinaria were firmly stuck to the cheeks. This result corroborates earlier observations by Claessens et al. (2008) who captured the images of C. umbratica in the act of removing pollinaria via their proboscises from putative hybrids in the Netherlands. We succeeded in photographing one individual of C. umbratica approaching an inflorescence of $P$. chlorantha with three pollinaria attached to its cheeks (i.e. from intermediate orchid individuals; see Fig. 2F). This observation may represent a proof of the potentiality of intermediate morphotypes to act not only as pollen recipients but also as pollen donors. In this case, crossing between intermediate forms could be effective (Claessens et al. 2008). It thus appears there is scope for hybridization and subsequent introgression, but this needs further testing. Furthermore, during our observations in one of the mixed populations (Bois Niau), we recorded two Autographa gamma individuals carrying both $P$. bifolia and $P$. chlorantha pollinaria on the proboscis and on the eye, respectively. The common and widespread noctuid A. gamma had already been described as one of the prominent pollinators of $P$. chlorantha in Sweden (Nilsson 1978), in south-central Scotland (Sexton \& McQueen 2005) and in Spain (Ruiz 2009). Moreover, this moth species had also already been observed visiting P. bifolia (Plepys, Ibarra, Francke \& Lofstedt 2002) and carrying its pollinaria (Ruiz 2009). Noctua pronuba too, which in this study was photographed with one $P$. chlorantha pollinium on the eye (Fig. 2G), had already been observed visiting $P$. chlorantha in Sweden (Hammarstedt 1980), in Central Scotland (Sexton 2014) and in the Iberian Peninsula (Ruiz 2009).

Thus, contrary to the literature (Nilsson 1983), which mentions mostly sphingids (especially Deilephila species) as the potential vector of hybridization, our observations show that it may well be possible that both orchid species are mainly pollinated by noctuid moths, and more specifically by C. umbratica and A. gamma effectively carrying pollinaria of both Platanthera species, with $C$. umbratica even observed carrying pollinaria of morphologically intermediate individuals. However, the dominance of these specific noctuids may be a matter of local and regional occurrence, influenced too by the availability of vegetation types, with other 

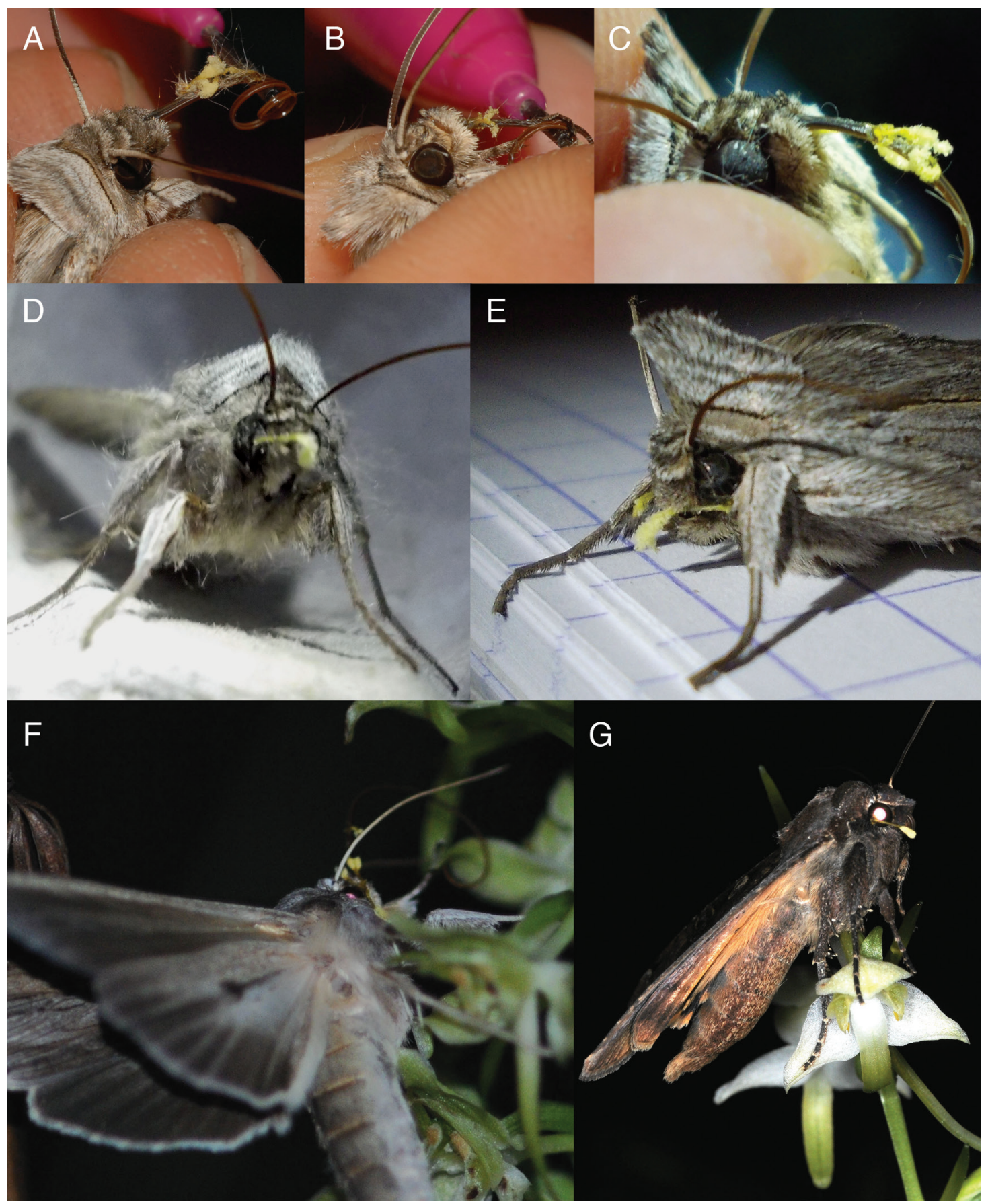

FiguRe 2. A-B: Bois Niau: two individuals of Cucullia umbratica with two pollinaria of $P$. bifolia on the proboscis (pictures D. Tyteca); C-D-E: Botton: three individuals of Cucullia umbratica, one with P. bifolia pollinaria on the proboscis, one with one P. chlorantha pollinarium on the eyes, and the other with two intermediates' pollinaria on the cheeks (pictures F. Esposito); F-G: Botton: Cucullia umbratica visiting P. chlorantha inflorescence with one pollinarium stuck to the cheek (coming from intermediate plant) and two to the proboscis (coming from P. bifolia), and Noctua pronuba with one P. chlorantha pollinarium stuck to the eye (pictures Guy Deflandre). 
Cucullia and Plusiinae species being pollinators at sites in other regions (Hammarstedt 1980, Nilsson 1983, Sexton 2014).

Most noctuids and sphingids are described as strong fliers, able to cover large distances (Nieminen \& Hanski 1998). Specifically, A. gamma and N. pronuba have been recorded to move distances of several hundred kilometres (Chapman et al. 2010, 2012, Hu, Lim, Reynolds, Reynolds \& Chapman 2016, Waring, Townsend, \& Lewington 2009). Their high mobility, both in terms of routine, daily movements (Slade et al. 2013) as in terms of (partial) migratory behaviour, possibly may have important effects on pollen dispersal ability and the extent of hybridization (Brys, Broeck, Mergeay \& Jacquemyn 2014).

Reproductive isolation as well as the level of introgression are generally controlled through three kinds of integrated interactions: temporal, ethological (i.e. pollinators reacting to floral fragrances and to nectar availability) and morphological (i.e. interactions between the morphology of pollinators and the morphology of columns and spurs) (Esposito et al. unpublished, Nilsson 1983, 1985). Within the framework of the Platanthera study system, we hypothesize that the mechanical barrier preventing (or reducing) effective hybridization involves that the pollinia of $P$. chlorantha may often not be adequately placed in order to fit the position of $P$. bifolia's stigma. This hypothesis contrasts with the alternative hypothesis, which suggests that the mechanical barrier may be due to the improper placement of pollinia from intermediate plants on visiting moths (Nilsson 1983). However, both hypotheses may fit with the rarity of real hybrid individuals, but does not explain why those intermediate plants, which appear to belong mainly to the gene pool of $P$. bifolia, appear in mixed populations. A previous hypothesis was formulated to give an explanation for the presence of these intermediate individuals (Esposito et al. unpublished). It seems that among those intermediate plants, the individuals tending towards $P$. chlorantha (which have a greater distance between their viscidia, and which flower earlier) are positively selected in order to attract and exploit $P$. chlorantha pollinators too. We have evaluated the validity of this hypothesis by exploring the effect of morphological traits on phenotypic selection through observing the relationship between plant trait expression and male versus female fitness, as a result of the interactions with pollinators (Esposito et al. unpublished). Thus, it seems that there is higher morphological variability within $P$. bifolia when the species comes in sympatry with $P$. chlorantha, probably because there is a higher selective pressure exerted by $P$. chlorantha's pollinators. However, we do not know if Platanthera species just respond plastically to environmental conditions or whether they are in a process of early speciation and specialization in response to local pollinators.

In conclusion, although our study shows that noctuids have the potential to cause hybridization in Platanthera, more observational and genetic research is needed. Studies that test successful pollen deposition across species, whilst assessing pollen dispersal distances, are essential in order to eventually (dis)prove hybridization is actually happening, and to hence better understand Platanthera-pollinator networks.

ACKNOWLEDGMEnTS. We thank Thomas Henneresse (UCL) and Guy Deflandre for their participation in the field research. This study was supported by grants-in-aid from the Fonds Scientifique de Recherche of the Université catholique de Louvain. This is paper BRC 389 from the Biodiversity Research Centre of UCL

\section{LiteRATURE CITED}

Argue, C. L. (2012). Platanthera Group. Pollination Biology of North American Orchids 1, 109-121.

Bateman, R. M. (2005). Circumscribing and interpreting closely related orchid species: Platanthera, Dactylorhiza and the crucial role of mutation. Journal of the Hardy Orchid Society 2, 104-111.

Bateman, R. M. \& Sexton, R. (2008). Is spur length of Platanthera species in the British Isles adaptively optimized or an evolutionary red herring? Watsonia 27 , $1-21$.

Bateman, R. M., James, K. E. \& Rudall, P. J. (2012). Contrast in levels of morphological versus molecular divergence between closely related Eurasian species of Platanthera (Orchidaceae) suggests recent evolution with a strong allometric component. New Journal of Botany 2, 110-148.

Boberg, E., Alexandersson, R., Jonsson, M., Maad, J., Ågren, J. \& Nilsson, L. A. (2013). Pollinator shifts 


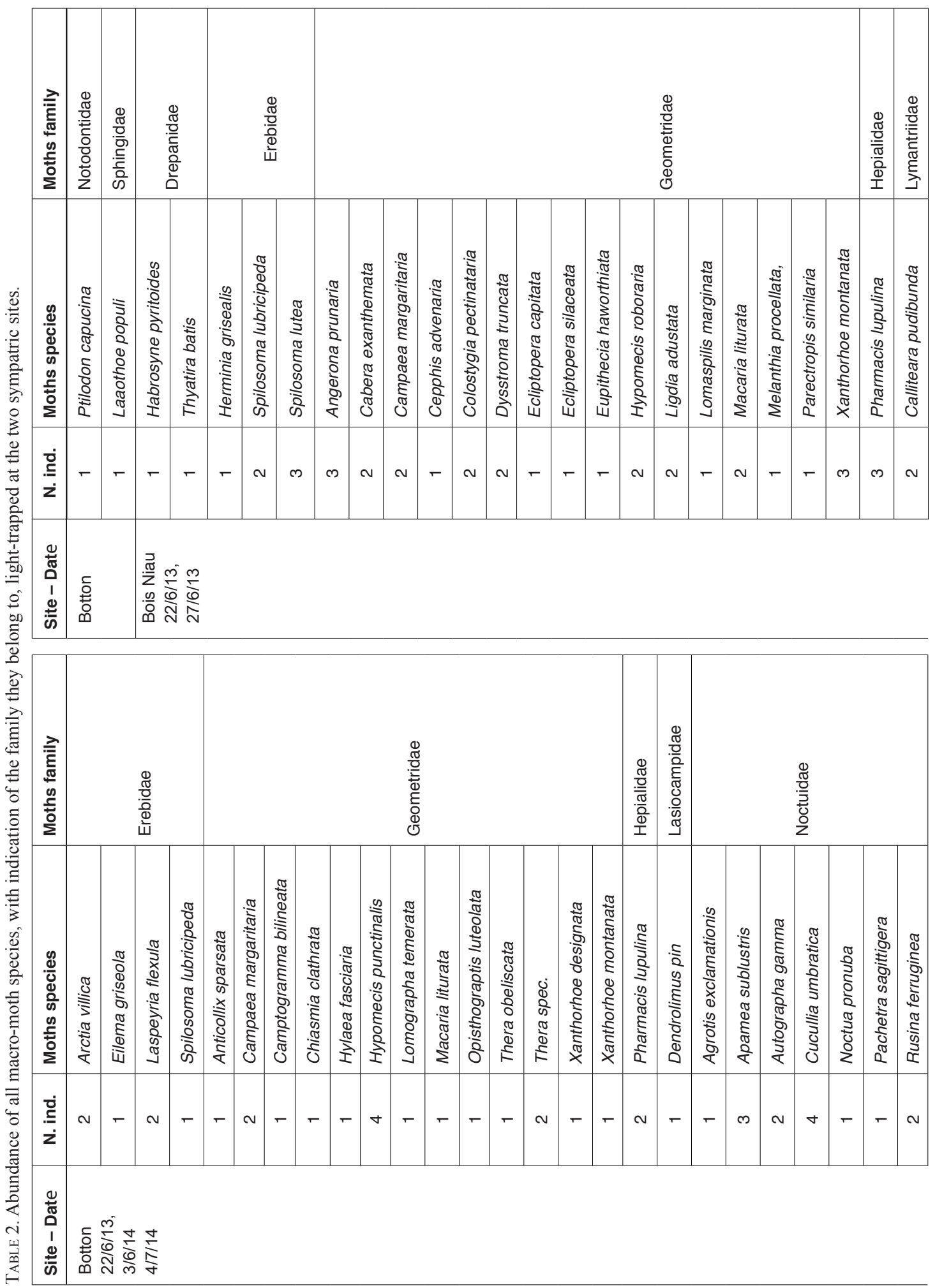



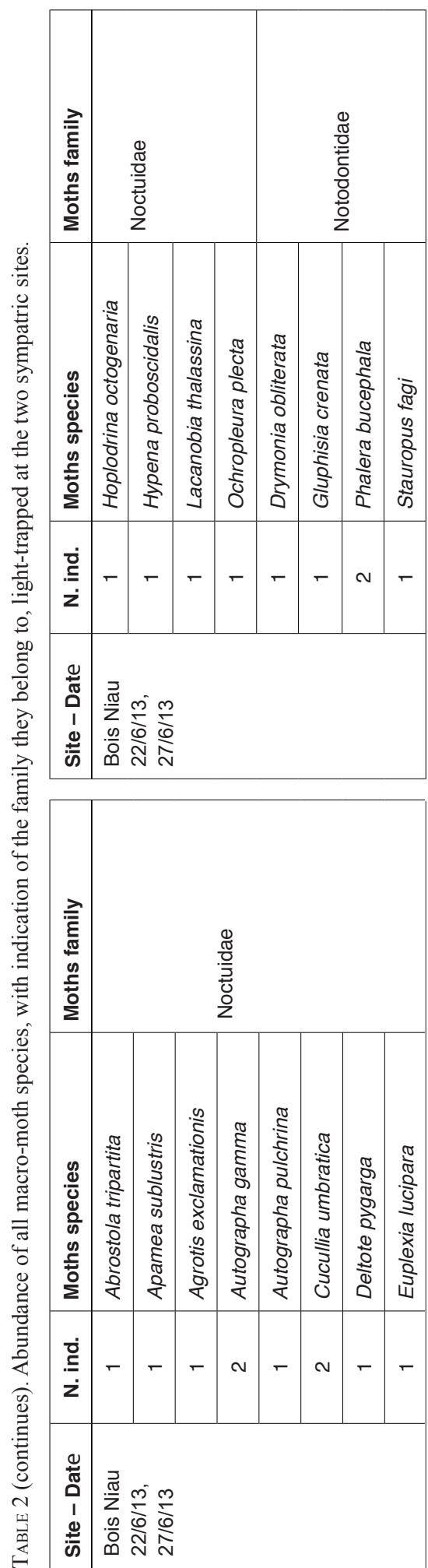

and the evolution of spur length in the moth-pollinated orchid Platanthera bifolia. Annals of Botany 113, 267275.

Bournérias, M., Prat, D. et al. (2005). Les Orchidées de France, Belgique et Luxembourg, 2nd ed. Mèze: Biotope.

Brys, R., Broeck, A. V., Mergeay, J. \& Jacquemyn, H. (2014). The contribution of mating system variation to reproductive isolation in two closely related Centaurium species (Gentianaceae) with a generalized flower morphology. Evolution 68, 1281-1293.

Catling, P. M. \& Catling, V. R. (1991). A synopsis of breeding systems and pollination in North American orchids. Lindleyana 6, 187-210.

Chapman, J. W., Nesbit, R. L., Burgin, L. E., Reynolds, D. R., Smith, A. D., Middleton, D. R. \& Hill, J. K. (2010). Flight orientation behaviors promote optimal migration trajectories in high-flying insects. Science 327, 682685.

Chapman, J. W., Bell, J. R., Burgin, L.E., Reynolds, D. R., Pettersson, L. B., Hill, J.K., Bonsall, M. B. \& Thomas, J.A. (2012). Seasonal migration to high latitudes results in major reproductive benefits in an insect. Proceedings of the National Academy of Sciences USA 109, 14924 14929.

Claessens, J. \& Kleynen, J. (2006). Anmerkungen zur Hybridbildung bei Platanthera bifolia und $P$. chlorantha. Journal Europäischer Orchideen 38, 3-28.

Claessens, J. \& Kleynen, J. (2011). The flower of the European orchid - Form and function. Geulle, Netherlands.

Claessens, J., Gravendeel, B. \& Kleynen, J. (2008). Cucullia umbratica L. als Bestaüber von Platanthera x hybrida Bruegg. in Süd-Limburg (Niederlande). Journal Europäischer Orchideen 40, 73-84.

Cozzolino, S. \& Widmer, A. (2005). Orchid diversity: an evolutionary consequence of deception? Trends in Ecology \& Evolution 20, 487-494.

Darwin, C. R. (1862). On the various contrivances by which British and foreign orchids are fertilised by insects and the good effects of intercrossing. London: John Murray.

Darwin, C. R. (1877). On the various contrivances by which British and foreign orchids are fertilised by insects. 2nd ed. London: John Murray.

Delforge, P. (2005). Guide des orchidées d'Europe, d'Afrique du Nord et du Proche-Orient. 3rd ed. Paris: Delachaux et Niestlé, Les guides du naturaliste.

Esposito, F., Jacquemyn, H., Waud, M. \& Tyteca, D. (2016). Mycorrhizal fungal diversity and community composition in two closely related Platanthera (Orchidaceae) species. PLoS One 11 (10): e0164108. doi:10.1371/journal.pone.0164108. 
Hahn, M. \& Brühl, C. A. (2016). The secret pollinators: an overview of moth pollination with a focus on Europe and North America. Arthropod-Plant Interactions 10, 21-28.

Hammarstedt, O. (1980). Plusiinae (Lep., Noctuidae) as pollinators of Platanthera chlorantha (Orchidaceae). Entomologisk Tidskrift 1014, 115-118.

Hapeman, J. R. (1997). Pollination and floral biology of Platanthera peramoena (Orchidaceae). Lindleyana 12, 192-5.

Hapeman, J. R. \& Inoue, K. (1997). Plantpollinator interactions and floral radiation in Platanthera (Orchidaceae). In: T.J. Givnish \& K.J. Sytsma (eds): Molecular Evolution and Adaptive Radiation. New York: Cambridge University Press, Cambridge, UK, pp 433-454.

Heath, J. (1965). A genuinely portable MV light trap. Entomologist's Record and Journal of Variation 77, 236-238.

Hu, G., Lim, K. S., Reynolds, D. R., Reynolds, A. M. \& Chapman, J. W. (2016). Wind-Related Orientation Patterns in Diurnal, Crepuscular and Nocturnal HighAltitude Insect Migrants. Frontiers in Behavioral Neuroscience 10, 32.

Inoue, K. (1985). Reproductive biology of two Platantherans (Orchidaceae) in the island of Hachijo. Japanese Journal of Ecology 35, 77-83.

Johnson, S. D. \& Edwards, T. J. (2000). The structure and function of orchid pollinaria. Plant Systematics and Evolution 222, 243-269.

Karasawa, K. (2003). Species Orchidacearum. Tokyo, Japan: Japan Broadcasting Publishing.

Kühsel, S. \& Blüthgen, N. (2015). High diversity stabilizes the thermal resilience of pollinator communities in intensively managed grasslands. Nature communication 6, 7989.

Maad, J. \& Nilsson, L. A. (2004). On the mechanism of floral shifts in speciation: gained pollination efficiency from tongue- to eye-attachment of pollinaria in Platanthera (Orchidaceae). Biological Journal of the Linnean Society 83, 481-495.

Macgregor, C. J., Pocock, M. J., Fox, R. \& Evans, D. M. (2015). Pollination by nocturnal Lepidoptera, and the effects of light pollution: a review. Ecological entomology 40, 187-198.

Merckx, T., Feber, R. E., Riordan, P., Townsend, M. C., Bourn, N. A. D, Parsons, M. S. \& Macdonald, D.W. (2009a). Optimizing the biodiversity gain from agrienvironment schemes. Agriculture, Ecosystems and Environment 130, 77-182.

Merckx, T., Feber, R. E., Dulieu, R. L, Townsend, M. C., Parsons, M. S., Bourn, N. A. D, Riordan, P. \&
Macdonald, D. W. (2009b). Effect of field margins on moths depends on species mobility: Field-based evidence for landscape-scale conservation. Agriculture, Ecosystems and Environment 129, 302-309.

Merckx, T., Marini, L., Feber, R. E. \& Macdonald, D. W. (2012a). Hedgerow trees and extended-width field margins enhance macro-moth diversity: implications for management. Journal of Applied Ecology 49, 13961404.

Merckx, T., Feber, R. E., Hoare, D. J., Parsons, M. S., Kelly, C. J., Bourn, N. A. D. \& Macdonald, D. W. (2012b). Conserving threatened Lepidoptera: towards an effective woodland management policy in landscapes under intense human land-use. Biological Conservation 149, 32-39.

Nieminen, M. \& Hanski, I. (1998). Metapopulations of moths on islands: a test of two contrasting models. Journal of Animal Ecology 67, 149-160.

Nilsson, L. A. (1978). Pollination ecology and adaptation in Platanthera chlorantha (Orchidaceae). Botaniska Notiser 131, 35-51.

Nilsson, L. A. (1983). Processes of isolation and introgressive interplay between Platanthera bifolia (L.) Rich and $P$. chlorantha (Custer) Reichb. (Orchidaceae). Botanical Journal of the Linnean Society 87, 325-350.

Nilsson, L. A. (1985). Characteristics and distribution of intermediates between Platanthera bifolia and $P$. chlorantha (Orchidaceae) in the Nordic countries. Nordic Journal of Botany 5, 407-419.

Nilsson, L. A. (1988). The evolution of flowers with deep corolla tubes. Nature 334, 147-149.

Perko, M. (1997). Beobachtungen zu einigen Hybriden aus der Familie der Orchideen (Orchidaceae) in Kärnten / Österreich, inkl. Dactylorhiza x juennensis M. Perko, nothosp. nat. nov.- Carinthia II, 187/107, 89-101.

Perko, M. (2004). Die Orchideen Kärntens. Klagenfurt: Arge Naturschutz.

Peter, C. I., Coombs, G., Huchzermeyer, C. F., Venter, N., Winkler, A. C., Hutton, D., Papier, L. A., Dold, A. P. \& Johnson, S. D. (2009). Confirmation of hawkmoth pollination in Habenaria epipactidea: Leg placement of pollinaria and crepuscular scent emission. The South African Journal of Botany 75, 744-75.

Plepys, D., Ibarra, F., Francke, W. \& Lofstedt, C. (2002). Odour-mediated nectar foraging in the silver $\mathrm{Y}$ moth, Autographa gamma (Lepidoptera: Noctuidae): behavioural and electrophysiological responses to floral volatiles. Oikos 99, 75-82.

Raguso, R. A. \& Willis, M. A. (2005). Synergy between visual and olfactory cues in nectar feeding by wild hawkmoths, Manduca sexta. Animal Behaviour 69, 407-418. 
Robertson, J. L. \& Wyatt, R. (1990). Evidence for pollination ecotypes in the yellow-fringed orchid, Platanthera ciliaris. Evolution 44, 121-133.

Ruiz, J. L. (2009). Lepidoptera visitantes y polinizadores potenciales de Platanthera sp. en el Pirineo (Huesca y Lérida) y el macizo Cazorla-Segura (Jaén, España) (Lepidoptera). Boletín Sociedad Entomológica Aragonesa 45, 485-487.

Schiestl, F. P. \& Schlüter, P. M. (2009). Floral isolation, specialized pollination, and pollinator behavior in orchids. Annual review of entomology 54, 425-446.

Sexton, R. (2014). The Moth Pollinators of Greater Butterfly Orchids Platanthera chlorantha in Central Scotland. Journal of the Hardy Orchid Society 11, 14-22.

Sexton, R. \& McQueen, A. E. D. (2005). Greater Butterflyorchids: Platanthera chlorantha (Custer) Reichenbach. Forth Naturalist and Historian 27, 77-90.

Slade, E. M., Merckx, T., Riutta, T., Bebber, D. P., Redhead, D., Riordan, P. \& Macdonald, D. W. (2013). Life history traits and landscape characteristics predict macro-moth responses to forest fragmentation. Ecology 94, 1519-1530.

Steen, R. (2012). Pollination of Platanthera chlorantha (Orchidaceae): new video registration of a hawkmoth (Sphingidae). Nordic Journal of Botany 30, 623-626.

Steen, R. \& Mundal, D. (2013). New video registration of Autographa pulchrina (Haworth, 1809) (Lepidoptera, Noctuidae) and Sphinx pinastri L., 1758 (Lepidoptera, Sphingidae) pollinating Platanthera bifolia latiflora (Orchidaceae) in Norway. Norwegian Journal of Entomology 60, 57-61.
Suetsugu, K. \& Fukushima, S. (2014a). Bee pollination of the endangered orchid Calanthe discolor through a generalized food-deceptive system. Plant Systematics and Evolution 300, 453-459

Suetsugu, K, \& Fukushima, S. (2014b). Pollination biology of the endangered orchid Cypripedium japonicum in a fragmented forest of Japan. Plant Species Biology 29, 294-299.

Tollsten, L. \& Bergström, L. J. (1993). Fragrance chemotypes of Platanthera (Orchidaceae) - the result of adaptation to pollinating moths? Nordic Journal of Botany 13, 607-613.

Waring, P, Townsend, M, \& Lewington, R. (2009). Field guide to the moths of Great Britain and Ireland, 2nd ed. Oxford: British Wildlife Publishing.

Weiner, C. N., Werner, M., Linsenmair, K. E. \& Blüthgen, N. (2014). Land-use impacts on plant-pollinator networks: interaction strength and specialization predict pollinator declines. Ecology 95, 466-474.

Wester, P. \& Lunau, K. (2016). Plant-Pollinator Communication. Advances in Botanical Research DOI: 10.1016/bs.abr.2016.10.004

Westwood, A. R. \& Borkowsky, C. L. (2004). Sphinx moth pollinators for the endangered western prairie fringed orchid, Platanthera praeclara in Manitoba, Canada. Journal of the Lepidopterists 'Society 58, 13-20

Wood, J. J., Beaman, R. S. \& Beaman, J. H. (1993). The plants of Mount Kinabalu 2: Orchids. London, England: Royal Botanic Gardens, Kew.

Young, M. (1997). The natural history of moths. London: Poyser Natural History. 
LANKESTERIANA 